\title{
ВЛАСТЬ НАДЕЖД: ОТСТАИВАНИЕ ИНФРАСТРУКТУРЫ В НОВЫХ ГОРОДСКИХ РАЙОНАХ
}

Городские инфраструктуры- важные основания городской жизни и городской политики. Кризис больших политических программ с их абстрактными целями и неопределенными временными горизонтами способствовал формированию политик повседневности, центральным пунктом которых стали городские инфраструктуры. Ее отсутствие, ненадлежащее состояние или дефицит является предметом переговоров между различными городскими агентами и основанием их противостояния. Центральный вопрос статьи: как именно жители новых районов отстаивают свои инфраструктурные требования, тем самым нарушая привилегию властей и девелоперов на развитие масштабных инфраструктурных проектов. Статья основана на материалах полевого исследования, проведенного в 2019-2020 гг. в новом жилом районе Подмосковья. Отстаивание надежд и оспаривание привилегий властных агентов происходит благодаря созданию горожанами динамичной, насыщенной событиями аффективной среды, в которой (вос)производится идея должного состояния инфраструктуры. Эта среда формируется одновременными действиями жителей на разных площадках, которые связываются согласованной версией происходящего, артикулируемой через локальные цифровые гражданские медиа-тематические группы в ВКонтакте, Инстаграм, Telegram, созданные и контролируемые местными жителями. Идея долженствования, предлагаемая и отстаиваемая

Оксана Николаевна Запорожец- к. социол.н., заведующая Научно-учебной лабораторией социальных исследований города, Национальный исследовательский университет «Высшая школа экономики», Москва, Россия. Электронная почта: ozaporozhets@hse.ru

Яна Александровна Багина - аспирантка, Аспирантская школа по социологическим наукам; стажер-исследователь, Научно-учебной лаборатории социальных исследований города, Национальный исследовательский университет «Высшая школа экономики», Москва, Россия. Электронная почта: ybagina@hse.ru 
местными жителями, основана на базовом аргументе о необходимости инфраструктуры, разделении ответственности за ее создание между властями, девелоперами и местными жителями. Последние рассматриваются как основная движущая сила изменений, создатели требований, на основе которых оцениваются происходящие события. Создание динамичной, содержательно и аффективно насыщенной среды, которая становится способом давления на власти и девелоперов, происходит за счет множества действий местных жителей на различных (иногда взаимоисключающих) аренах, подчиненных общей цели- отстаиванию их интересов. В процессе онлайн-коммуникации, разворачивающейся в локальных цифровых медиа, наиболее активные местные жители вовлекают в процесс своих соседей. Общими усилиями происходит «расколдовывание» логики создания инфраструктуры и передел ответственности различных агентов, апелляция к эмоциям и общему знанию о районе. Хотя влияние горожан на развитие материальных инфраструктур оценить сложно, можно утверждать, что их усилиями создается и успешно развивается гражданская инфраструктура.

Ключевые слова: инфраструктура, новые жилые районы, инфраструктурные надежды, гражданские медиа, локальный активизм

DOI: 10.17323/727-0634-2021-19-2-269-284

Городские инфраструктуры- важное основание городской политики (Larkin 2013). Здания, дороги, транспорт, водо-, электро- и теплоснабжение, социальные объекты- эти и многие другие инфраструктуры вплетены в повседневную жизнь каждого горожанина, они реальны и понятны, их готовы отставивать жители и обещать власти. Отсутствие, недостаточность инфраструктур или сбои в их функционировании особенно остро ощущаются жителями новых городских районов, где во многом они являются «обещанием будущего, данным в настоящем» (Appel et al. 2018: 27). Именно с их строительством и изменением местные жители связывают свои надежды на лучшее будущее района. Однако инфраструктурные надежды предполагают не только ожидания, но и готовность их отстаивать.

Центральный вопрос статьи: как именно жители новых районов отстаивают свои инфраструктурные надежды? Рассмотрение этого вопроса позволяет показать, что действия жителей нарушают привилегию властей и девелоперов на развитие масштабных инфраструктурных проектов. Мы полагаем, что отстаивание надежд и оспаривание привилегий властных агентов происходит благодаря созданию горожанами динамичной, насыщенной событиями, аффективной среды, в которой (вос)производится идея должного состояния инфраструктуры. Эта среда формируется одновременными действиями жителей на разных площадках, которые связываются согласованной версией происходящего, артикулируемой через локальные цифровые гражданские медиа. 


\section{Место действия}

В центре нашего анализа-жилой комплекс Путилково ${ }^{1}$. Он находится в деревне Путилково Московской области, примыкающей к Москве с северо-запада. Плотно застроенный 15-25-этажными домами район явно не соответствует административному статусу деревни. Уже несколько лет жилой комплекс активно строится: первые дома сданы в 2014 г., сдача последних планировалась на 2020 г. Поскольку для официальной статистики деревня остается белым пятном, о ее населении можно говорить лишь приблизительно. Местные жители сообщают примерно о 60 тыс. человек, из которых 30-35 тыс. приходится на ЖК Путилково.

Путилково является типичным для российских мегаполисов примером нарушенных обещаний и неоправдавшихся (ко времени написания статьи) надежд. Одна из причин сложившейся ситуации заключается в резком изменении компанией-девелопером первоначального плана застройки. Стремясь к увеличению прибыли, она отменила строительство паркингов и культурного центра, заменив их жилыми домами, а также заморозила возведение физкультурно-оздоровительного комплекса. По ряду причин задерживалось и открытие социальных объектов: школ, детских садов, поликлиники. Жители Путилкова несколько лет ежедневно испытывали на себе все несовершенства дорожной сети и общественного транспорта, заставлявшие их стоять в многочасовых пробках или в длинных очередях на автобусы. Остро ощущалась нехватка собственной станции скорой помощи и отдела полиции.

Статья основана на исследовании, проведенном авторами в 20192020 гг. с использованием методов полуструктурированного интервью, наблюдения и анализа локальных социальных сетей. Всего проведено 20 интервью с местными жителями, включая двух активистов, входящих в инициативную группу района. Участниками исследования стали жители Путилкова в возрасте от 22 лет до 41 года, преимущественно с высшим образованием, проживающие в ЖК от года до четырех лет. Наблюдение проходило весной-летом 2019 г. Также мы проанализировали посты в группе «Путилково - территория добра» в ВКонтакте (2016-2020), связанные с инфраструктурными объектами и провели несистематическое онлайн-наблюдение в других местных социальных медиа-Инстаграм и Telegram-канале Putilkovo_info.

\section{Инфраструктурные надежды}

Создание инфраструктуры, через которое проходят все новые жилые районы, делает явными связанные с ней ожидания горожан. Для описания такого «вторжения будущего в настоящее» (Reeves 2017: 717) мы предлагаем

\footnotetext{
${ }^{1}$ Бывшее, а теперь неофициальное название- Мортонград (или сокращенный вариант-Мортон).
} 
использовать понятие «инфраструктурные надежды» (эквивалент promise of infrastructure, infrastructural hope) - переживания и активное воспроизводство жителями представлений о том, какой должна быть инфраструктура и как может изменится их жизнь с ее появлением или изменением (Appel et al. 2018). Инфраструктурные надежды-это сочетание технологий, людей и практик (Jensen, Morita 2017), а потому инфраструктуры имеют собственную историю, которая начинается еще на этапе проектирования, продолжается в процессе строительства, принимает новую форму с началом ее использования и меняется в процессе, переживая сбои и поломки, устаревание и ремонт (Gupta 2018).

Исследователи рассматривают инфраструктуру как своеобразный символ будущего, который ассоциируется с качественным улучшением жизни, прогрессом, современностью, комфортом, технологичностью, пространственной и социальной включенностью (Harvey, Knox 2015; Jensen 2017; Reeves 2017). Они особенно подчеркивают аффективную насыщенность этих представлений: инфраструктуры являются объектами желания, они «очаровывают» и «обещают» лучшую жизнь (Harvey, Knox 2012; Appel et al. 2018). С этим связана специфическая темпоральная рациональность инфраструктур: разочарование в инфраструктурных проектах прошлого зачастую не противоречит оптимизму относительно строительства и изменения инфраструктуры в будущем (Reeves 2017). Именно поэтому люди, жизни которых касается это строительство, готовы активно отстаивать свои инфраструктурные надежды, а власти-манипулировать ожиданием горожан (Auyero, Swistun 2009). Аффективность надежд, в свою очередь, умножает формы предпринимаемых для их отстаивания действий (Laszczkowski 2019).

Опираясь на исследования инфраструктур, мы считаем, что именно инфраструктурные надежды можно рассматривать как отправную точку для возникновения практик защиты и продвижения горожанами своего видения будущего. В отличие от более рациональных «интересов», надежды показывают эмоциональную значимость материальных объектов, пусть и существующих только на бумаге. Мы полагаем, что в процессе отстаивания своих инфраструктурных надежд горожане создают идею долженствования- дискурсивный конструкт, побуждающий ряд акторов к строительству и изменению инфраструктуры через принятие на себя обязательств.

\section{Цифровые гражданские медиа: говорить о мире на своих условиях}

Как и с помощью каких механизмов создается идея долженствования, которая переводит надежды на определенное состояние инфраструктуры в достаточно категоричные требования, озвучиваемые и отстаиваемые местными жителями? Говоря о способах отстаивания горожанами своих 
интересов, Анна Желнина и Елена Тыканова предлагают использовать понятие «гражданские инфраструктуры»- «оборудование для интерактивных и динамических процессов согласования интересов и развития города, [которые] позволяют игрокам коммуницировать, договариваться, формулировать задачи и принимать решения о судьбе города» (Желнина, Тыканова 2019: 168).

В своей статье мы обратимся к цифровым гражданским медиа как к элементу гражданских инфраструктур, который является важным инструментом обозначения, согласования и продвижения инфраструктурных надежд. Увеличение их значимости связано с доступностью цифровых технологий и постоянным ростом числа их пользователей во всем мире, включая Россию (Gerbaudo 2012; Lim 2015). Цифровые гражданские медиа (citizen media) - это онлайн-площадки (чаты и каналы в мессенджерах, группы и аккаунты в социальных сетях), создаваемые и поддерживаемые горожанами, а также агенты, дискурсы, практики и физические артефакты, связанные с производством, артикуляцией и отстаиванием идей на этих площадках (Baker, Blaagaard 2016; Stephansen, Trere 2019). Цифровые гражданские медиа дают возможность «несистемным игрокам продвигать контент, противоречащий доминирующим дискурсам, делать явными скрытые реалии», создавать конкурирующие системы смыслов (Stephansen, Trere 2019: 1). Благодаря гражданским медиа горожане обретают возможность говорить о мире на своих условиях, создают и осознают свою агентность, используя для этого собственные языки, смыслы и символы (Rodriguez 2011:24). C помощью гражданских медиа горожане фреймируют ситуацию- вырабатывают и продвигают собственную версию происходящего, основанную на общих представлениях и смыслах (Benford, Snow 2000).

Мы не идеализируем роль гражданских цифровых медиа и их способность создавать самостоятельную повестку. Упаковывая информацию в привычные медиаформаты, они время от времени жертвуют содержанием ради формы подачи информации (Lim 2015). И все же цифровые гражданские медиа становятся важными самостоятельными агентами. Они действуют и мобилизуют горожан, включая их в онлайн-коммуникацию (Bennett, Segerberg 2013). Гражданские медиа являются одной из возможных оптик рассмотрения социальных сетей и онлайн-групп, которые возникают в городских районах. Локальные онлайн-сообщества не являются исключительно инструментом декларации и отстаивания горожанами своих надежд и интересов, выполняя множество функций- общения, обмена информацией, формирования локальной нормативности и контроля (Давыдов, Логунова 2018; Чернышева, Гизатуллина 2021). И все же нельзя отрицать, что они формируют и продвигают определенную гражданскую повестку (Зеленцов 2015; Павлов 2016), ведь их пользователи легко переходят от разговоров о своих повседневных делах и увлечениях к обсуждению общих проблем и способов их решения. Постоянные переходы от личного 
к общественному рутинизируют гражданскую повестку, превращают ее в привычную часть городской коммуникации.

\section{Отстаивание инфраструктурных надежд: производство идеи долженствования}

Долженствование изначально не было центральной темой нашего исследования. Однако общение с местными жителями и мониторинг местных социальных сетей постоянно обращали наше внимание на изобретательность и неутомимость, с которыми путилковцы отстаивают свои надежды на изменение инфраструктуры. Казалось, не было такой возможности, которой бы они не воспользовались- от вывода поста о местных проблемах в топ сайта Пикабу до официальных обращений президенту России. Многообразие и разнонаправленность действий местных жителей, их эмоциональная заряженность, динамичность и изменчивость сформировали среду, в которой (вос)производится идея должного состояния инфраструктуры. Эта среда стала способом давления на власти и девелопера, побуждая их выполнять свои обязательства. Далее мы рассмотрим, как формируется эта среда: кто и как соединяет разрозненные практики в согласованную версию происходящего, какие действия предпринимают путилковцы, чтобы отстоять свои надежды, как увеличивается число местных жителей, вовлеченных в борьбу за инфраструктуру, и, наконец, как создается аффективная насыщенность их требований и действий.

\section{Сборка и создание согласованного нарратива}

Предпринимаемые местными жителями действия основываются на идее долженствования-необходимости наличия определенных инфраструктурных объектов и возложения на власти и девелопера обязательств по их строительству. Долженствование обычно касается не отдельных объектов, а их совокупности. К примеру, требование местных жителей о строительстве культурного центра может сопровождаться напоминанием о необходимости расширения дороги. Долженствование- часть общего видения ситуации, создаваемого местными жителями в ходе переговоров, отстаиваемого и продвигаемого ими на различных аренах. В Путилкове такое видение только вырабатывается: отдельные позиции обозначены четко и однозначно, в отношении других согласие пока не достигнуто. Исследовательница гражданского активизма Франческа Полетта называет такую не до конца проясненную, находящуюся в процессе согласования версию происходящего нарративом (Polletta 1998). По ее мнению, нарратив предваряет появление фрейма- более однозначной и согласованной интерпретативной рамки. Ее наличие дает сторонникам определенных идей возможность объединиться, заручиться поддержкой сочувствующих и ослабить влияние противников (Snow, Benford 1988). 
В случае Путилкова мы говорим именно о производстве нарратива, который создается и поддерживается местными жителями в ходе трудоемкой, затратной по времени, требующей навыков и консолидации усилий сборки разрозненной информации. Наиболее согласованной частью нарратива- связанной версии событий-является его базовый аргумент: нарушение властями и девелоперами обязательств по строительству и сдаче в эксплуатацию инфраструктурных объектов, вызывающее у жителей необходимость отстаивать свои надежды на должное состояние инфраструктуры. Этот аргумент решает три задачи- производит должное (наличие инфраструктуры), обозначает ответственных за ее создание (властей, девелоперов и самих жителей) и отдает приоритет позиции жителей. Базовый аргумент отстаивается разными способами и риторическими средствами, но не подвергается сомнению. Согласованность нарратива является важным фактором мобилизации и действенности требований местных жителей (Auyero, Swistun 2009), поскольку множественность нарративов, как версий происходящих событий, может «парализовывать» горожан, лишать их способности к действию из-за невозможности разобраться в происходящем, информационной перегрузки, трудности солидаризации с определенным мнением, учитывая его недостатки, обозначенные конкурентами (Ibid).

Согласованность нарратива достигается жителями Путилкова в ходе сборки информации и подчинения ее базовому аргументу. Полетта отмечает, что для нарратива важно соединить события и обеспечить базовый уровень ясности общей повестки (Polletta 1998). Сборка аккумулирует и выстраивает в последовательность действия основных участников событий (местных жителей, властей, девелоперов), предпринимаемые ими со времени активного заселения района. Сборка сопряжена с поиском местными жителями труднодоступных или крайне разрозненных источников о строительстве и развитии местной инфраструктуры, включая официальные жалобы и ответы на них, судебные постановления, репортажи путилковцев из залов суда или встреч с девелопером и местными властями, а также информацию об акциях самих жителей.

Выработка местными жителями согласованного нарратива происходит в созданной ими сети онлайн-площадок, на которой размещаются все материалы с комментариями и пояснениями. На этих же площадках путилковцы рассказывают о происходящих в районе событиях, значительная часть которых связана с инфраструктурой и невыполненными властями или девелоперами обещаниями. Основными блоками этой цифровой инфраструктуры являются Telegram-канал Putilkovo_info (пять тыс. подписчиков), группы «Путилково- территория добра» в Йнстаграм (семь тыс. подписчиков) и ВКонтакте (5 800). Онлайн-платформы связаны друг с другом общей повесткой, дублированием и репостами материалов, общими подписчиками. 
Лидирующую роль в выработке согласованной версии происходящего играют участники местной инициативной группы, администрирующие сеть онлайн-площадок. Сама группа организована по принципу айсберга: несколько публичных фигур, которые представляют позицию местных жителей в судах, СМИ, переговорах с властями, и невидимое большинство (несколько десятков человек), которое поддерживает онлайн-платформы, разрабатывает стратегию действий, готовит юридические документы.

Инициативная группа объединяет юристов, IT- и $P R$-специалистов и других профессионалов, чьи знания и социальный капитал используются для производства, артикуляции и продвижения согласованного нарратива. Активисты оперативно реагируют на происходящее, четко формулируют свою позицию и эффективно используют цифровые медиа для ее продвижения: «Это за час может выйти. И охват сразу десять тысяч человек» (интервью с участниками инициативной группы). При том, что финансовые и политические ресурсы группы уступают ресурсам властей или девелоперов, она уверенно выигрывает на символическом поле. Ее способность быть ньюсмейкером и ее версия событий востребована центральными телеканалами и другими новостными изданиями, неоднократно освещавшими события в Путилкове. При кажущейся единой повестке и стратегии действий в группе случаются разногласия. Ее позиция также не всегда совпадает с позициями местных жителей, однако в публичном пространстве разногласия уходят на второй план и не становятся основанием для раскола или масштабных внутренних конфликтов.

Участники инициативной группы вместе с местными жителями собирают воедино сведения об истории обживания района и актуальных событиях. История района представляется ими как череда (нарушенных) инфраструктурных обещаний властей или девелопера и действий жителей по отстаиванию своих надежд. Так, первая «летопись» Путилкова возникает в ответ на запрос официальных инстанций воссоздать историю борьбы за инфраструктуру:

[С нами] связались из аппарата Государственной Думы и попросили подготовить историю взаимодействия с застройщиками и госорганами! Нужна вся информация от первого рекламного буклета до последнего письма Путину! (13.09.2017, пост в группе в ВКонтакте)

Инициативная группа и местные жители постоянно проводят работу по связыванию настоящего и прошлого, апеллируя к обещанным, но многократно нарушенным срокам сдачи инфраструктурных объектов. Опираясь на установленные даты, жители контролируют девелоперов и местные власти: «Уже 4 года обещают открыть [поликлинику]... С переносами [власти] заврались так, что все даты поперепутали» $(17.09 .2020$, пост и дискуссия в Инстаграм). Контроль действий властей и девелоперов ведется также через постоянный мониторинг жителями всех возможных источников 
информации, включая распределение бюджета Московской области, проекты планировки территории, судебные решения, ответы на жалобы, публичные выступления, инсайдерскую информацию, ход строительства объектов инфраструктуры. Эта информация целенаправленно отслеживается и размещается в локальных медиа, сопровождаясь комментариями, которые устанавливают ее соответствие инфраструктурным надеждам жителей.

\section{Множественность действий}

Репертуар борьбы за инфраструктурные надежды включает множество действий. Путилковцы повторяют свои требования на разных аренах и с помощью разных инструментов, за счет чего создают и воспроизводят идею долженствования. Их требования адресованы чиновникам разного уровня и девелоперу, которым приписывается ответственность за изменение инфраструктуры и контроль над ней. Требования артикулируются с помощью многочисленных формальных инструментов гражданского участия: обращений в органы власти и местного самоуправления, писем депутатам Государственной думы, участия в официальных встречах и публичных слушаниях, подачи исков в суд, организации митингов, участия в местных выборах.

Однако в российских реалиях официальные способы участия горожан в принятии решений существенно ограничены (Шевцова, Бедерсон 2017; Шаталова, Тыканова 2018; Желнина, Тыканова 2019). Тем не менее активисты продолжают добиваться признания на официальном уровне, параллельно привлекая внимание к инфраструктурным проблемам района с помощью СМИ. Инициативная группа и местные жители с готовностью общаются с журналистами самых разных изданий и телеканалов, независимо от их направленности и аудитории: Россия 1, Первый канал, Дождь, Радио Свобода, Новые известия, Свободная пресса, РИАМО, Новострой-М. Важную роль в воспроизводстве идеи долженствования играют и созданные активистами гражданские медиа, где местные жители могут свободно высказывать свое мнение (Stephansen, Trere 2019). Надежды и требования относительно локальных инфраструктур практически ежедневно повторяются в постах и комментариях. Периодически в них отмечают официальные аккаунты чиновников (ВКонтакте и Инстаграм). В этом случае представители власти воспринимаются «скорее как объект воздействия, нежели как партнер в решении городских проблем» (Шевцова, Бедерсон 2017: 132).

\section{Вовлечение местных жителей}

Долженствование воспроизводится не только с помощью множества арен и инструментов, но и за счет поддержки местных жителей. В ежедневной онлайн-коммуникации инициативная группа распространяет информацию о местных инфраструктурах и обучает соседей отстаиванию своих надежд (Клеман и др. 2010; Clement 2015). Активисты расколдовы- 
вают инфраструктуру- показывают социальные отношения, которые стоят за ее устройством (Stephansen, Trere 2019). Они разъясняют обоснованность своих требований, ссылаясь на документально зафиксированные обязательства девелопера и местной администрации, делают публичным процесс коммуникации с ними, указывают властям и девелоперам на допущенные ими нарушения. Например, активисты подробно объясняли, как изменения в Правилах землепользования и застройки позволяют девелоперу строить новые дома на месте обещанного культурного центра, игнорируя мнение жителей (19.04.2018, пост в группе в ВКонтакте).

Вовлечение местных жителей происходит не только за счет информирования об устройстве инфраструктуры, но и с помощью рассказов о том, как можно воздействовать на работу других акторов. Способы воздействия включают публикацию шаблонов обращений в официальные инстанции, инструкций по созданию сообщений на «Доброделе» (интернет-портал, на котором жители Московской области могут сообщить о проблеме или задать вопрос органам исполнительной власти), информации о сборе подписей или сборе средств для отстаивания интересов жителей в суде, приглашения на встречи с журналистами и акции протеста. При сохранении лидирующей роли инициативной группы происходит активное включение местных жителей в производство долженствования через участие в обсуждениях и комментариях, публикацию видео и фотографий, фиксирующих инфраструктурные проблемы, а также через сам факт просмотра и лайки.

\section{Аффективно насыщенная среда}

Продвигая на онлайн-платформах идею должного состояния инфраструктуры, участники инициативной группы оперируют различными эмоциями (Van Kleef, Fischer 2016): возмущением, отчаянием, надеждой, иронией, которые позволяют им мобилизовать путилковцев. Разделяя и демонстрируя эти эмоции, местные жители преодолевают «аффективную лояльность доминирующим институтам» (Jasper 2011:296) и включаются в борьбу за достижение общей цели на различных аренах. Публикуя посты и поощряя онлайн-дискуссии, активисты дают путилковцам возможность «почувствовать себя уязвленными определенными обстоятельствами и одновременно вдохновиться возможностью совместно решить проблему» (McAdam et al. 1996: 5). В качестве «уязвляющих» обстоятельств активисты и местные жители рассматривают не только инфраструктурные проблемы, но и позицию чиновников и девелоперов: их равнодушие, обман, неисполнение обязательств. Эмоциональной поддержкой для местных жителей становится публичное признание их способности добиться воплощения своих инфраструктурных надежд. Солидарность и взаимопомощь местных жителей рассматриваются в онлайн-дискуссиях как гарантии достижения совместных целей, а сами цели оцениваются как реалистичные: вместе 
путилковцы оказались лишены доступа к необходимым инфраструктурам, вместе же смогут добиться изменений.

Эмоционально заряженное общение может как вдохновлять местных жителей на действия, так и демобилизовывать их. Некоторые путилковцы устают от эмоционального накала или осознают несоответствие своих эмоций эмоциям, принятым в сообществе, например, энтузиазму активистов. Для противостояния демобилизующим эмоциям и поддержания вовлеченности инициативная группа использует «механизмы поощрения»: обсуждение происходящего и убеждение в возможности победы (Jasper 2011). Активисты не используют эмоции для удержания местных жителей от действий, например, страх последствий или радость от достигнутого.

Частью создания аффективно насыщенной среды является использование аффективно насыщенного языка- вербального или визуального, подчеркивающего остроту проблемы. Местные жители регулярно делятся на онлайн-платформах своим возмущением по поводу инфраструктурных ограничений, называя Путилково аппендиксом (ненужной и проблемной частью Красногорского городского округа), деревней или гетто. Недовольство сложившейся ситуацией иногда облекается ими в форму рассказов или стихов, обращающихся не только к опыту, но и к воображению. В разговоре об инфраструктурных проблемах путилковцы широко используют визуальный язык: фотографии, видео, скриншоты онлайн-карт с пробками или стикеры для Telegram, иронично обыгрывающие местные проблемы. Популярные сюжеты путилковских фотографий- утренние пробки на выезде из района и дворы, плотно заставленные автомобилями. Ежедневное напоминание о трудностях не позволяет забыть их остроту.

Создавая информационно и эмоционально насыщенную среду, инициативная группа и жители Путилкова предпочитают не делать свои требования частью общей активистской повестки, которая объединила бы жителей новых районов Подмосковья, Москвы или других городов России. Предложения о сотрудничестве, поступавшие от других активистских групп после репортажей на центральных телевизионных каналах, не привели к общему действию. «Наша задача не создавать глобальное гражданское общество»,- утверждают местные активисты, ссылаясь на свой плотный рабочий график и занятость делами района. Свободно меняя масштаб взаимодействия и переходя на самые высокие уровни в коммуникации с властными инстанциями или общероссийскими медиа, местные активисты отказываются от масштабных альянсов с гражданскими объединениями, продолжая производить идею долженствования на локальном уровне.

\section{Заключение}

Городские инфраструктуры сегодня являются важной частью политик повседневности, во многом определяющих жизнь городов. В статье мы 
показываем, как жители нового района отстаивают свои инфраструктурные надежды, оспаривая привилегию городских властей и девелоперов на создание нормативности городской среды и сроков ее создания. Мы полагаем, что горожане фактически создают повестку, важнейшим пунктом которой является должное состояние инфраструктуры. Случай исследуемого нами нового жилого района показывает, что требования в отношении инфраструктуры касаются, как правило, не отдельных объектов, а их совокупности. Это связано с созданием активистами общей позиции относительно инфраструктуры и развития района. Отстаивание надежд происходит с помощью создания динамичной, содержательно и эмоционально насыщенной среды, продвигающей идею долженствования инфраструктурных объектов.

Действуя параллельно на различных аренах, используя широкий репертуар инструментов, многократно повторяя свои требования и объясняя действия, местные жители предлагают согласованный нарратив, описывающий происходящие в районе события. Он формируется и продвигается преимущественно с помощью локальных цифровых гражданских медиаонлайн-площадок, где аккумулируются разнообразные сведения об отстаивании требований, расколдовываются логики создания инфраструктур и ответственности различных агентов, происходит обучение способам гражданского участия. Жители и инициативная группа, отстаивающие идею долженствования, начинают восприниматься как агенты действия-с ними налаживают контакты местные власти, взаимодействуют СМИ.

За время нашего исследования в Путилкове произошли изменения: расширяется ведущая к нему дорога, строятся физкультурно-оздоровительный комплекс и паркинг, открыто отделение полиции. Сложно утверждать, что столь масштабные изменения материальной инфраструктуры произошли исключительно благодаря усилиям местных жителей, однако то, что эти усилия привели к развитию гражданской инфраструктуры, не подлежит сомнению.

\section{Список источников}

Давыдов С. Г., Логунова О.С. (2018) Сообщества московских районов в социальных медиа: контент и его модерация. Мониторинг общественного мнения: Экономические и сочиальные перемены, (1):204-221.

Желнина А. А., Тыканова Е. В. (2019) Формальные и неформальные гражданские инфраструктуры: современные исследования городского локального активизма в России. Журнал соииологии и социальной антропологии, 22 (1): 162-192.

Зеленцов М.В. (2015) Городские медиа: условия функционирования. Вопросы теории и практики журналистики, 4 (3): 262-272.

Клеман К., Мирясова О., Демидов А. (2010) От обывателей к активистам: зарождающиеся социальные движения в современной России. М.: Три квадрата.

Павлов А. В. (2016) Локальные городские сообщества в социальных сетях между «соседской» и «гражданской» коммуникацией. Лабиринт, (5): 46-57.

Чернышева Л., Гизатуллина Э. (2021) «Русские сезоны»: тротуарный балет на новых городских улицах в эпоху цифровых медиа. Е.Г. Лапина-Кратасюк, О.Н. Запорожец, А. Возьянов (ред.) Сети города. Люди. Технологии. Власть. М.: НЛО. 
Шаталова А.Н., Тыканова Е.В. (2018) Неформальные практики участников публичных слушаний (случай Санкт-Петербурга). Журнал социологии и соииальной антропологии, 21 (4): $63-84$.

Шевцова И. К., Бедерсон В. Д. (2017) «У власти точка зрения-молчание»: взаимодействие инициативных групп и органов местной власти в политике городского планирования. Политическая наука, (4): 111-136.

Appel H., Anand N., Gupta A. (2018) Introduction: Temporality, Politics, and the Promise of Infrastructure. In: N. Anand, A. Gupta, H. Appel (eds.) The Promise of Infrastructure. Durham: Duke University Press: 1-38.

Auyero J., Swistun D. A. (2009) Flammable: Environmental Suffering in an Argentine Shantytown. Oxford: Oxford University Press.

Benford R. D., Snow D. A. (2000) Framing Processes and Social Movements: An Overview and Assessment. Annual Review of Sociology, 26 (1): 611-39.

Bennett W.L., Segerberg A. (2013) The Logic of Connective Action: Digital Media and the Personalization of Contentious Politics. Cambridge: Cambridge University Press.

Baker M., Blaagaard B.B. (2016) Citizen Media and Public Spaces: Diverse expressions of citizenship and dissent. Abingdon: Routledge.

Clement K. (2015) Unlikely Mobilisations: How Ordinary Russian People Become Involved in Collective Action. European Journal of Cultural and Political Sociology, 2 (3-4): 211-240. Gerbaudo P. (2012) Tweets and the Streets: Social Media and Contemporary Activism. London: Pluto Press.

Gupta A. (2018) The Future in Ruins: Thoughts on the Temporality of Infrastructure. In: N. Anand, A. Gupta, H. Appel (eds.) The Promise of Infrastructure. Durham: Duke University Press: 62-79. Harvey P., Knox H. (2012) The Enchantments of Infrastructure. Mobilities, 7 (4): 521-536.

Harvey P., Knox H. (2015) Roads: An Anthropology of Infrastructure and Expertise. Ithaca: Cornell University Press.

Jasper J. M. (2011) Emotions and Social Movements: Twenty Years of Theory and Research. Annual Review of Sociology, (37): 285-303.

Jensen C. B. (2017) Pipe Dreams: Sewage Infrastructure and Activity Trails in Phnom Penh. Ethnos, 82 (4): 627-647.

Jensen C. B., Morita A. (2017) Introduction: Infrastructures as Ontological Experiments. Ethnos, 82 (4): 615-626.

Larkin B. (2013) The Politics and Poetics of Infrastructure. Annual Review of Anthropology, 42 (1): $327-343$.

Laszczkowski M. (2019) Encountering 'Micro-Dus': Material Entities, Affect, and Politics in Infrastructural Conflict in Italy. Ethnos, 85 (5): 938-956.

Lim M. (2015) Many Clicks but Little Sticks: Social Media Activism in Indonesia. In: N. Shah, P. P. Sneha, S. Chattapadhyay (eds.) Digital Activism in Asia (Reader). Lüneburg: Meson Press: $127-154$.

McAdam D., McCarthy J.D., Zald M.N. (1996) Comparative Perspectives on Social Movements. New York: Cambridge University Press.

Polletta F. (1998) 'It Was Like A Fever ...' Narrative and Identity in Social Protest. Social Problems, 45 (2): 137-159.

Reeves M. (2017) Infrastructural Hope: Anticipating 'Independent Roads' and Territorial Integrity in Southern Kyrgyzstan. Ethnos, 82 (4): 711-737.

Rodriguez C. (2011) Citizens' Media Against Armed Conflict: Disrupting Violence in Colombia. Minneapolis: University of Minnesota Press.

Snow D. A., Benford R. D. (1988) Ideology, Frame Resonance, and Participant Mobilization. International Social Movement Research, (1): 197-217.

Stephansen H.C., Trere E. (2019) Practice What You Preach? Currents, Connections, and Challenges in Theorizing Citizen Media and Practice. In: H.C. Stephansen, E. Trere (eds.) Citizen Media and Practice: Currents, Connections, Challenges. Abingdon: Routledge: 1-34.

Van Kleef G. A., Fischer A. H. (2016) Emotional collectives: How Groups Shape Emotions and Emotions Shape Groups. Cognition and Emotion, 30 (1):3-19. 
Oksana Zaporozhets, Yana Bagina

\title{
HOW HOPES BUILD THE CIVIC INFRASTRUCTURE OF NEW RESIDENTIAL AREAS
}

\begin{abstract}
Urban infrastructures are central to urban life and urban politics. The crisis of big political agendas with their abstract goals and uncertain time horizons resulted in the emergence of politics centered around urban infrastructures. Infrastructures become the field for negotiation and confrontation between different agents, especially in new residential areas that experience a deficit of public transportation and social services. The paper focuses on the residents of these districts, who stand up for their infrastructural hopes and thereby contest the monopoly of the authorities and developers to produce and manage large-scale urban infrastructures. The paper is based on fieldwork conducted by the authors across 2019 and 2020 in a new residential area of the Moscow Region. The data include semi-structured interviews, offline and online observations. To defend their hopes and challenge the privileged position of local authorities and developers, citizens create a dynamic, eventful, emotionally saturated environment that (re)produces the idea of infrastructure (and its characteristics) as a must. This environment is formed by residents, who simultaneously act on multiple arenas such as courts, mass media, public meetings, etc. Cooperating, residents frame the situation, i.e., develop and share a coherent vision of events articulated through digital citizen media. In doing so, they reveal the logic of infrastructures and the responsibilities of involved agents. This knowledge empowers residents to pursue their interests in various public arenas and pressure authorities and developers to follow the contract and keep their promises. While doing so, locals produce shared knowledge about the district and its problems. It is hard to assess to what degree citizen actions influence the development of material infrastructures; however, it can be concluded they do successfully create a civic infrastructure.
\end{abstract}

Key words: infrastructure, new residential areas, promise of infrastructure, infrastructural hopes, citizen media, local activism

DOI: 10.17323/727-0634-2021-19-2-269-284

\section{References}

Appel H., Anand N., Gupta A. (2018) Introduction: Temporality, Politics, and the Promise of Infrastructure. In: N. Anand, A. Gupta, H. Appel (eds.) The Promise of Infrastructure. Durham: Duke University Press: 1-38.

Oksana Zaporozhets - Cand. Sci (Sociol.), Head of the Laboratory of Urban Sociology, HSE University, Moscow, Russian Federation. Email: ozaporozhets@hse.ru

Yana Bagina - Doctoral Student, Doctoral School of Sociology; Research Assistant, Laboratory of Urban Sociology, HSE University, Moscow, Russian Federation. Email: ybagina@hse.ru 
Auyero J., Swistun D. A. (2009) Flammable: Environmental Suffering in an Argentine Shantytown. Oxford: Oxford University Press.

Benford R. D., Snow D. A. (2000) Framing Processes and Social Movements: An Overview and Assessment. Annual Review of Sociology, 26 (1): 611-39.

Bennett W.L., Segerberg A. (2013) The Logic of Connective Action: Digital Media and the Personalization of Contentious Politics. Cambridge: Cambridge University Press.

Baker M., Blaagaard B. B. (2016) Citizen Media and Public Spaces: Diverse Expressions of Citizenship and Dissent. Abingdon: Routledge.

Chernysheva L., Gizatullina Je. (2021) 'Russkie sezony': trotuarnyj balet na novyh gorodskih ulicah v jepohu cifrovyh media ['Russian Seasons': Sidewalk Ballet on New City Streets in Digital Media Age]. In: E. G. Lapina-Kratasjuk, O.N. Zaporozhec, A. Voz'janov (eds.) Seti goroda. Ljudi. Tehnologii. Vlast' [City Networks. People, Technology, Power]. Moscow: Novoe literaturnoe obozrenie.

Clement K. (2015) Unlikely Mobilisations: How Ordinary Russian People Become Involved in Collective Action. European Journal of Cultural and Political Sociology, 2 (3-4):211-240.

Clement K., Miryasova O., Demidov A. (2010) Ot obyvateley k aktivistam: zarozhdayushchiyesya sotsial'nyye dvizheniya v sovremennoy Rossii [From Citizen to Activists: Incipient Social Movements in Modern Russia]. Moscow: Tri kvadrata.

Davydov S. G., Logunova O. S. (2018) Soobshhestva moskovskih rajonov v social'nyh media: kontent i ego moderacija [Moscow Districts' Social Media Communities: Content and its Moderation]. Monitoring obshhestvennogo mnenija [Monitoring of Public Opinion], (1):204-221.

Gerbaudo P. (2012) Tweets and the Streets: Social Media and Contemporary Activism. London: Pluto Press.

Gupta A. (2018) The Future in Ruins: Thoughts on the Temporality of Infrastructure. In: N. Anand, A. Gupta, H. Appel (eds.) The Promise of Infrastructure. Durham: Duke University Press: 62-79.

Harvey P., Knox H. (2012) The Enchantments of Infrastructure. Mobilities, 7 (4): 521-536.

Harvey P., Knox H. (2015) Roads: An Anthropology of Infrastructure and Expertise. Ithaca: Cornell University Press.

Jasper J. M. (2011) Emotions and Social Movements: Twenty Years of Theory and Research. Annual Review of Sociology, (37): 285-303.

Jensen C. B. (2017) Pipe Dreams: Sewage Infrastructure and Activity Trails in Phnom Penh. Ethnos, 82 (4): 627-647.

Jensen C. B., Morita A. (2017) Introduction: Infrastructures as Ontological Experiments. Ethnos, 82 (4): 615-626.

Larkin B. (2013) The Politics and Poetics of Infrastructure. Annual Review of Anthropology, 42 (1): 327-343.

Laszczkowski M. (2019) Encountering 'Micro-Dus': Material Entities, Affect, and Politics in Infrastructural Conflict in Italy. Ethnos, 85 (5): 938-956. 
Lim M. (2015) Many Clicks but Little Sticks: Social Media Activism in Indonesia. In: N. Shah, P. P. Sneha, S. Chattapadhyay (eds.) Digital Activism in Asia (Reader). Lüneburg: Meson Press: $127-154$.

McAdam D., McCarthy J.D., Zald M.N. (1996) Comparative Perspectives on Social Movements. New York: Cambridge University Press.

Pavlov A. V. (2016) Lokal'nye gorodskie soobshchestva v sotsial'nykh setyakh: mezhdu 'sosedskoi' i 'grazhdanskoi' kommunikatsiei [Local Urban Communities in Social Networks: Between 'Neighbor' and 'Civil' Communication]. Labirint [Labyrinth], (5):46-57.

Polletta F. (1998) 'It Was Like A Fever ...' Narrative and Identity in Social Protest. Social Problems, 45 (2): 137-159.

Reeves M. (2017) Infrastructural Hope: Anticipating 'Independent Roads' and Territorial Integrity in Southern Kyrgyzstan. Ethnos, 82 (4): 711-737.

Rodriguez C. (2011) Citizens> Media Against Armed Conflict: Disrupting Violence in Colombia. Minneapolis: University of Minnesota Press.

Shatalova A. N., Tykanova E. V. (2018) Neformal'nyye praktiki uchastnikov publichnykh slushaniy (sluchay Sankt-Peterburga) [Informal Practices of the Public Hearings Participants (The Case of St. Petersburg)]. Zhurnal sotsiologii i sotsial'noy antropologii [Journal of Sociology and Social Anthropology], 21 (4): 63-84.

Shevtsova I.K., Bederson V.D. (2017) 'U vlasti tochka zreniya- molchaniye': Vzaimodeystviye initsiativnykh grupp i organov mestnoy vlasti v politike gorodskogo planirovaniya ['The Authorities Prefer to Keep Silent': Interaction Between Initiative Groups and Local Authorities in Urban Planning Policies]. Politicheskaya Nauka [Political Science], (4):111-136.

Snow D. A., Benford R. D. (1988) Ideology, Frame Resonance, and Participant Mobilization. International Social Movement Research, (1): 197-217.

Stephansen H.C., Trere E. (2019) Practice What You Preach? Currents, Connections, and Challenges in Theorizing Citizen Media and Practice. In: H.C. Stephansen, E. Trere (eds.) Citizen Media and Practice: Currents, Connections, Challenges. Abingdon: Routledge: 1-34.

Van Kleef G. A., Fischer A.H. (2016) Emotional Collectives: How Groups Shape Emotions and Emotions Shape Groups. Cognition and Emotion, 30 (1):3-19.

Zelentsov M. V. (2015) Gorodskie media: uslovija funkcionirovanija [Urban Media: Operating Conditions]. Voprosy teorii i praktiki zhurnalistiki [Theoretical and Practical Issues of Journalism], 4 (3): 262-272.

Zhelnina A.A., Tykanova E. V. (2019) Formal'nye i neformal'nye grazhdanskie infrastruktury: sovremennye issledovanija gorodskogo lokal'nogo aktivizma v Rossii [Formal and Informal Civic Infrastructure: Contemporary Studies of Urban Local Activism in Russia]. Zhurnal sociologii i social'noj antropologii [The Journal of Sociology and Social Anthropology], 22 (1): 162-192. 